\title{
Costureiras no Território da Atenção Primária à Saúde: Trabalho em Domicílio e Vulnerabilidades
}

\author{
Seamstresses in the Territory of Primary Health Care: Home-based \\ Work and Vulnerabilities
}

\author{
Taiane Araújo dos Prazeres Ornelas ${ }^{1}$ \\ Mônica Angelim Gomes de Lima² \\ Elizabeth Costa Dias ${ }^{3}$ \\ Robson da Fonseca Neves ${ }^{4}$
}

\section{RESUMO}

Objetivo: O estudo trata da configuração do trabalho domiciliar de costureiras, suas trajetórias de vida e de trabalho e implicações para o cuidado à saúde no território de uma unidade de saúde da família (USF). Metodologia: Optou-se por um delineamento de estudo exploratório, com abordagem socioantropológica, que examinou: a) a trajetória das mulheres para se tornarem costureiras; b) as condições de trabalho em casa e suas repercussões no contexto familiar; $c$ ) a visibilidade desses usuários-trabalhadores para os profissionais de saúde e suas demandas nas interações com a USF. O diário de campo registrou os elementos que marcaram a presença do trabalho das costureiras no domicílio, por meio da observação sistemática e direta do trabalho domiciliar e de uma entrevista em profundidade que permitiu a reconstrução dialógica do trabalho de costura em casa. Resultados: As mulheres negras, com baixa escolaridade e qualificação profissional foram predominantes no estudo. As costureiras possuíam casa própria e mantinham o sustento de filhos e netos com diferentes funções de produção e reprodução social. As trajetórias de trabalho reafirmam a negação dos direitos trabalhistas e previdenciários e a piora da saúde e da qualidade de vida ao longo do tempo. As interações com a USF se dão para o atendimento aos familiares e exame preventivo. O tempo de espera impulsiona os usuários-trabalhadores em condições agudas para os serviços privados. Conclusão: $\mathrm{O}$ trabalho domiciliar expôs as vulnerabilidades das costureiras, seja pela desproteção social, pela invisibilidade da condição de trabalhadoras e pelo trabalho domiciliar no território de abrangência de uma USF em área urbana.

\section{DESCRITORES}

Trabalho. Gênero. Saúde do Trabalhador. Vulnerabilidade. Mulher.

\begin{abstract}
Objective: This study deals with the configuration of home-based work for seamstresses, their life and work trajectories and implications for the health care in the territory of the Primary Health Care Service (PHCS). Methodology: We opted for an exploratory study design, with a socio-anthropological approach, which examined: a) the trajectories of women to become seamstresses; b) working conditions at home and their repercussions in the family context; c) the visibility of these user-workers by health professionals and their demands in the interactions with the PHCS. The field diary recorded the elements that marked the presence of the seamstresses' work at home, through systematic and direct observation of domestic work and an in-depth interview that allowed the dialogical reconstruction of sewing work at home. Results: Black women, with low education and professional qualification predominated in the study. The seamstresses had their own home and maintained the sustenance of children and grandchildren with different functions of production and social reproduction. Work trajectories reaffirm the denial of labor and social protection and the worsening of health and quality of life over time. The interactions with the PHCS are for the family care and preventive examination. Waiting time drives users-workers in acute conditions to private services. Conclusion: Home-based work exposed the vulnerabilities of the seamstresses, either due to social deprotection, the invisibility of the condition of workers or the domestic work in the territory covered by a PHCS in an urban area.
\end{abstract}

DESCRIPTORS

Work. Gender. Worker's Health. Vulnerability. Women.

${ }^{1}$ Mestre em Saúde, Ambiente e Trabalho pelo Programa de Pós-Graduação em Saúde, Ambiente e Trabalho da Universidade Federal da Bahia - PPGSAT/UFBA, Salvador, Bahia, Brasil.

${ }^{2}$ Doutora em Saúde Coletiva, Professora do Departamento de Medicina Preventiva e Social da Faculdade de Medicina da Bahia e do Programa de Pós-Graduação em Saúde, Ambiente e Trabalho, Universidade Federal da Bahia, Salvador, Bahia, Brasil.

${ }^{3}$ Médica Sanitarista e do Trabalho, Professora da Área de Saúde do Trabalhador da Faculdade de Medicina da Universidade Federal de Minas Gerais, Belo Horizonte, Minas Gerais, Brasil.

${ }^{4}$ Doutor em Saúde Pública, Professor dos Programas de Pós-Graduação em Fisioterapia e Saúde Coletiva da Universidade Federal da Paraíba, João Pessoa, Paraíba, Brasil. 
A expansão do trabalho no domicílio é uma das características marcantes das transformações do mundo do trabalho, na atualidade, em decorrência da desconcentração e fragmentação dos processos produtivos, em pequenas e médias unidades ${ }^{1}$. Nessa situação predomina o trabalho de mulheres e a superposição com o trabalho reprodutivo doméstico. A inserção das mulheres no mercado de trabalho não as isenta da execução das atividades domésticas e do cuidado com os filhos. Esse papel, culturalmente instituído, tem sido utilizado para facilitar a inserção das mulheres no trabalho precarizado, traduzido na contratação de jornada de trabalho parcial, ausência de garantias sociais e trabalhistas e salários reduzidos $^{2}$. Como decorrência, elas optam pelo trabalho em domicílio que permite conciliar o trabalho assalariado e o cuidado da família ${ }^{3}$.

De acordo com Brito ${ }^{4}$, o trabalho feminino sempre esteve associado à precariedade. Apesar da instabilidade e o desemprego atingirem homens e mulheres, para elas a carga de fragilidade e incertezas é maior.

Essa mistura entre produção e reprodução do trabalho das mulheres não é recente², mas os impactos da reestruturação produtiva em curso, em escala global, atingem de forma desigual as mulheres, os homens jovens e os idosos ${ }^{2}$.

No âmbito do sistema único de saúde (SUS), a atenção primária à saúde (APS) tem papel central na implantação da Política Nacional de Saúde do Trabalhador e da Trabalhadora (PNSTT) ${ }^{5}$. No modelo de atenção vigente a APS é considerada como orientadora da rede e coordenadora do cuidado em saúde e tem como premissas o trabalho em equipe e a responsabilidade sanitária por um determinado território e sua população adscrita. Ao incluir as ações de saúde do trabalhador no cotidiano das equipes, a APS assume ações programáticas, coproduzidas com os usuários e outros atores sociais, articulando a Rede Nacional de Atenção Integral à Saúde do(a) Trabalhador(a) (RENAST) na Rede de Atenção à Saúde (RAS) ${ }^{5}$.

A estratégia de saúde da família (ESF), em especial, apresenta potencial para romper com a invisibilidade das condições de saúde-doença e trabalho, permitindo identificar aspectos relacionados à precarização do trabalho e às vulnerabilidades nos espaços urbanos decorrentes do trabalho no domicílio, peridomicílio e extradomiciliar. Também pode contribuir para o enfrentamento da desproteção social e prevenir a exposição a riscos à saúde e ocorrência de acidentes e doenças relacionadas ao trabalho. Desse modo qualifica a assistência e permite desenvolver ações de vigilância epidemiológica e dos ambientes e condições de trabalho, contribuindo para a saúde desses trabalhadores ${ }^{6}$.

O estudo do trabalho domiciliar das costureiras, a partir da abordagem das equipes da ESF busca iluminar a discussão sobre vulnerabilidades entre mulheres trabalhadoras em um dado território. O modelo proposto por Ayres et al. ${ }^{7}$ permite a identificação de planos de determinação interdependentes da vulnerabilidade individual, social e programática. Para este estudo, interessa especialmente a vulnerabilidade social, enquanto grau de informação sobre os problemas de saúde e a forma como essas informações são inseridas na prática, facilitando ou não a aproximação ou o distanciamento do exercício da cidadania e da participação política ${ }^{7}$. 
Este estudo explora a configuração do trabalho domiciliar de costureiras, a partir de suas trajetórias de vida e trabalho e algumas interações dessas usuárias-trabalhadoras com o serviço de saúde, em território de abrangência de uma unidade de saúde da família (USF), no Município de Salvador, Bahia, Brasil.

\section{METODOLOGIA}

Buscou-se conhecer o trabalho em domicílio de mulheres costureiras, em um determinado território, por meio da aproximação do seu cotidiano de trabalho, da vida familiar e comunitária. Este estudo exploratório está apoiado na perspectiva socioantropológica, recorrendo a métodos que privilegiam os cenários, os diálogos e a reflexividade, da primeira autora, enquanto profissional de saúde da USF do território estudado, com base no seu envolvimento com atores sociais (profissionais de saúde e usuárias-trabalhadoras) na coprodução dos dados, que possibilitaram o exercício interpretativo ${ }^{8}$.

Este tipo de produção privilegia as interações humanas e o caráter intersubjetivo da pesquisa empírica e a solidariedade com os grupos pesquisados, tendo como base a igualdade humana fundamental ${ }^{9}$. Neste artigo são discutidas três aspectos: a) as trajetórias de mulheres para tornarem-se costureiras; b) as condições do trabalho domiciliar e as suas repercussões no contexto familiar e; c) a visibilidade dessas usuárias-trabalhadoras para os profissionais de saúde da USF e a perspectiva dessas mulheres nas interações com a USF. Considerou-se que os elementos gênero, raça e classe social apontam vulnerabilidades e interseccionalidades.
Foram realizadas entrevistas em profundidade sobre a trajetória das mulheres para se tornar costureira, o processo de trabalho domiciliar, seus componentes internos e externos ao domicílio, a relação percebida entre saúde e trabalho, trabalho e família, a composição da renda e o gerenciamento da produção no trabalho de costureira. Foi utilizada abordagem etnográfica, na perspectiva da reconstrução dialógica sobre o trabalho de costura no domicílio, com registro em diário de campo sobre o lugar, as pessoas e os elementos que marcavam a presença do trabalho das costureiras no domicílio, além da observação sistemática e direta do trabalho, no período de agosto/2017 a março/ $2018^{10}$.

Os ACS participaram ativamente do estudo e receberam um roteiro para fazer o mapeamento dos trabalhos domiciliares e a descrição dos trabalhos identificados em sua microárea na situação de trabalho domiciliar. Eles foram responsáveis pelo convite inicial aos moradores para o estudo e acompanharam as visitas.

Participaram sete mulheres que tinham a costura como única fonte ou como complemento de renda e trabalhavam no domicílio, considerando o tipo e o volume de trabalho, os produtos e as relações com o consumidor. Cada domicílio foi visitado pelo menos duas vezes.

O processo interpretativo recorreu à compreensão da composição 'figura e fundo' do trabalho, domicílio, família, em uma leitura dialógica entre descrição, interação e contexto, recorrendo à narrativa e a cena do trabalho no domicílio. Apoiou-se em uma perspectiva compreensiva inspirada no construcionismo social, que assume a construção da realidade 
como produção intersubjetiva e a problematização de sentidos atribuídos à saúde, ao cotidiano e às interações produzidas pelo trabalho e o encontro entre essas usuárias trabalhadoras e trabalhadores de saúde ${ }^{11}$.

Esta pesquisa foi aprovada pelo Comitê de Ética em Pesquisa da Faculdade de Medicina da Universidade Federal da Bahia (FAMEB/UFBA) sob o parecer 2.232.052, nomes fictícios foram utilizados.

\section{RESULTADOS E DISCUSSÃO}

O Bairro da Federação caracteriza-se pela população economicamente heterogênea, abrangendo famílias de classe média, pobres e miseráveis. No local, coexistem luxuosos condomínios e áreas de aglomerados subnormais, compostos por domicílios de baixo padrão construtivo, que se amontoam em ruas e vielas, cortadas por escadarias com trechos de difícil acesso.

Os resultados das observações permi- tiram a identificação de 87 trabalhadores em distintas atividades produtivas em domicílio no território, sendo 24 costureiras, 18 na produção de alimentos (marmitas, salgadinhos, bolos, doces, geladinhos, picolés, etc.), 15 na venda de alimentos e bebidas e o restante em salão de beleza, fabricação de produtos de limpeza, protéticos, concertos de eletroeletrônicos, dentre outros.

$O$ estudo permitiu que os profissionais da ESF envolvidos rompessem a barreira da invisibilidade do trabalho e da presença de trabalhadores, até então não percebidos, tendo evidenciado também a magnitude do trabalho de mulheres costureiras a domicílio.

A escolha das costureiras decorreu do número expressivo de trabalhadoras identificadas no território, trabalhando em processos artesanais, no domicílio e, por vezes, inseridas na cadeia produtiva da facção na indústria têxtil. Segundo Neves e Pedrosa², a reestruturação na indústria de confecção acontece há alguns anos e está baseada em processos

Quadro 1. Principais características sociodemográficas das informantes e produtos fabricados

\begin{tabular}{|c|c|c|c|c|c|c|c|}
\hline NOME & IDADE & FILHOS & $\begin{array}{c}\text { ESTADO } \\
\text { CIVIL }\end{array}$ & RAÇA/COR & ESCOLARIDADE & $\begin{array}{c}\text { RENDA } \\
\text { MENSAL }\end{array}$ & $\begin{array}{c}\text { O QUE } \\
\text { COSTURA }\end{array}$ \\
\hline Madalena & 40 & 01 & Solteira & Preta & $\begin{array}{c}\text { Ensino médio } \\
\text { completo }\end{array}$ & $\begin{array}{c}\text { Renda da } \\
\text { costura }\end{array}$ & Roupa \\
\hline Rosa & 45 & 01 & Separada & Preta & $\begin{array}{c}\text { Ensino médio } \\
\text { completo }\end{array}$ & $\begin{array}{c}\text { Renda da } \\
\text { costura }\end{array}$ & Roupa \\
\hline Miralva & 67 & Não & Solteira & Parda & $\begin{array}{c}\text { Fundamental } \\
\text { incompleto }\end{array}$ & $\begin{array}{c}\text { Aposen- } \\
\text { tada }\end{array}$ & Roupa \\
\hline Valdira & 45 & Não & Divorciada & Preta & $\begin{array}{c}\text { Ensino médio } \\
\text { completo }\end{array}$ & $\begin{array}{c}\text { Renda da } \\
\text { costura }\end{array}$ & Roupa \\
\hline Ana & 58 & 04 & Solteira & Preta & $\begin{array}{c}\text { Fundamental } \\
\text { incompleto }\end{array}$ & $\begin{array}{c}\text { Renda da } \\
\text { costura }\end{array}$ & Roupa \\
\hline Noêmia & 76 & Não & Solteira & Parda & $\begin{array}{c}\text { Fundamental } \\
\text { incompleto }\end{array}$ & $\begin{array}{c}\text { Aposen- } \\
\text { tada }\end{array}$ & Roupa \\
\hline Zuleide & 52 & 01 & Solteira & Preta & Ensino médio \\
completo & $\begin{array}{c}\text { Renda da } \\
\text { costura }\end{array}$ & $\begin{array}{c}\text { Artesana- } \\
\text { to típico } \\
\text { regional }\end{array}$ \\
\hline
\end{tabular}


de segmentação do trabalho, terceirização de mão de obra, potencializando a discriminação da inserção da mulher no mercado de trabaIho. A fragmentação dos processos produtivos como característica da organização de trabalho nas facções transfere a produção total ou parcial para outros espaços produtivos, incluindo o domicílio.

As principais características sociodemográficas das costureiras e do produto do trabaIho estão resumidas no Quadro 1. A narrativa da trajetória de cada participante inicia-se com uma frase que expressa a experiência vivenciada na profissão.

\section{As costureiras da Federação}

"Nunca trabalhei de carteira assinada". Madalena é uma mulher de 40 anos e completou o antigo segundo grau. Não tem companheiro, mora com a filha de quatro anos, em uma casa de quatro cômodos e construção inacabada, sem piso e reboco, localizada em uma avenida (beco) onde as casas são bem próximas umas das outras. Ela comprou a laje da casa onde morava de aluguel e construiu sua casa. Tomou um empréstimo que é pago com a renda da costura. Trabalhou por alguns anos em uma fábrica em Salvador, sem vínculo formal de trabalho. Após brigar com uma colega de trabalho, pediu para sair, comprou as máquinas e iniciou a produção em casa. Confecciona fardamentos para empresas, escolas e jalecos em quantidade. No caso de fardamentos para empresas e jalecos, os clientes compram os materiais e ela fornece a mão de obra. Esses intermediários, revendem o produto para as lojas no centro da cidade e pagam um valor mínimo por peça confeccionada. No caso do fardamento escolar, ela negocia diretamente com as escolas, faz o orçamento, compra o material necessário, confecciona e entrega o pedido pronto, obtendo faturamento maior.

"Sempre costurei para ganhar meu trocadinho", diz Ana que tem 58 anos, é solteira e não tem companheiro. Estudou até a quinta série do antigo $1^{\circ}$ grau. Mora em uma casa pequena e bem organizada de dois andares, localizada na mesma avenida da casa de Madalena. Tem quatro filhos e dois netos. Mora com um filho no andar de baixo. No andar superior moram uma filha, o genro e dois netos. É ela quem cuida dos netos de 04 anos e 10 anos, durante o dia, para a mãe das crianças trabalhar. Começou a trabalhar com costura em uma fábrica, aos 12 anos, e nunca exerceu outra atividade ao longo da vida. Trabalhou em diversas fábricas em Salvador, algumas com carteira assinada e outras como diarista e sempre manteve clientes em casa. Confecciona diversos tipos de roupas: vestido, calça, blusa, moda íntima e biquínis, utilizando diversos tipos de tecidos, que algumas vezes são comprados por Ana e em outros casos são levados pelas clientes. Após sofrer um acidente no trabalho, não reconhecido pela empresa decidiu comprar umas máquinas e iniciar a produção exclusivamente em casa. Contribuiu para o Instituto Nacional do Seguro Social (INSS) no período que trabalhou com carteira assinada, mas atualmente não o faz. 
"Antes de ir para costura, eu fazia qualquer coisa que achasse para ganhar dinheiro". Valdira tem 45 anos e concluiu o antigo segundo grau. É divorciada e vive sozinha em uma casa pequena e bem organizada que construiu em cima da casa da mãe. Concluiu o curso de técnico em nutrição, mas nunca atuou. Pensa em fazer faculdade de moda para aperfeiçoar seu trabalho. Começou a trabalhar com costura aos 17 anos, como aprendiz e antes disso trabalhava fazendo "bico" em serviços gerais. Estudava pela manhã e à tarde ia para o atelier. Já trabalhou em diversas fábricas de costura em Salvador, até que resolveu montar sua fabricação em casa. Em todas as fábricas nas quais trabalhou teve a carteira de trabalho assinada e assim, contribuiu para a previdência social, porém hoje não o faz. Mesmo quando trabalhava em fábrica, costurava em casa para complementar a renda e não perder as clientes fixas.

"Em casa é diferente, pois meu patrão sou eu mesma”. Rosa tem 45 anos e mora em uma casa de cinco cômodos, herança da mãe, com o filho de 17 anos. Foi casada por dezenove anos e há dois anos está separada. Concluiu o antigo segundo grau. Mora próximo de uma irmã que também costura e lhe dá suporte nos períodos de maior demanda. Já trabalhou como auxiliar de salão de beleza e como auxiliar administrativo em escritório e sempre costurou. Fez um curso profissionalizante de corte e costura no Serviço Nacional de Aprendizagem Industrial (SENAI), pois queria ter uma profissão. Quando foi demitida, resolveu produzir exclusivamente, em casa.
Costura todo tipo de roupas: vestido, saia, calça, bermuda, artesanato, toalha, lençol, dentre outras. Seus clientes aparecem a partir da indicação de outros. Tem interesse em ampliar a produção para distribuir para lojas e, para isso, pretende buscar orientação no Serviço Brasileiro de Apoio às Micro e Pequenas Empresas (SEBRAE) e constituir uma empresa. Nunca trabalhou em fábrica de costura. Tem alguns anos de contribuição para o INSS, referente ao período que trabalhou com carteira assinada, mas desde que trabalha em casa não faz contribuição previdenciária.

"Apanhava porque costurava só para trás", Zuleide tem 52 anos, mora com a filha de 11 anos, a mãe e uma irmã. A casa é própria e tem dois andares. Aprendeu a costurar com a avó. Trabalhou como escriturária em um banco privado por oito anos, mas desde essa época já fazia artesanato (boneca de pano e boneca de louça) em casa para vender e aumentar a renda. Considerando que a carga horária do banco era de 6 horas, começou a trabalhar em uma fábrica como costureira, no período das $16 \mathrm{~h}$ às $22 \mathrm{~h}$. Após um desentendimento no banco pediu para sair e começou a confeccionar bonecas baianas características do artesanato regional. Teve duas lojas montadas no Pelourinho (um atelier e uma loja), para ficar mais perto dos clientes, chegando a empregar sete funcionários. Foi atingida fortemente pela crise econômica de 2006, com o cancelamento de grandes pedidos. Em 2014, retomou a produção em casa. Atualmente, confecciona vários modelos e tamanhos de bonecas baianas. Nos meses 
de maior demanda, fornece a sua produção para lojas do porto e aeroporto de Salvador e Mercado Modelo. Também trabalha, há três anos com transporte escolar, em carro próprio e concilia a produção das bonecas com o transporte escolar de crianças que estudam em escolas do bairro.

"A máquina para mim é uma atividade para ocupar minha mente", Miralva tem 67 anos, aposentada, solteira, mora sozinha e não teve filhos. A casa é própria e o irmão mora no andar de cima. Veio do interior do estado onde trabalhava na roça, plantando milho e feijão, aos 26 anos e começou a trabalhar em uma pequena confecção de roupas e tornou-se costureira. Trabalhou em diversas fábricas de roupas em Salvador como costureira, relatando longas jornadas de trabalho, com poucos intervalos de descanso. Quando saiu da última fábrica para cuidar dos pais idosos que moravam com ela, já tinha tempo suficiente para se aposentar, mas não o fez. Os pais morreram há cerca de dois anos. Atualmente apresenta diversos problemas de saúde que a impedem de costurar por longos períodos sentada, realizando pequenos reparos, bainhas e colocação de zíper para vizinhos.

Sintetizando, as costureiras entrevistadas possuem casa própria, fazem parte da segunda ou terceira geração de mulheres nas mesmas condições de vida e trabalho, são donas de seus meios de produção e compraram suas máquinas de costura quando saíram das fábricas e empregos formais. Possuem entre três e cinco máquinas de costura, algumas delas de porte industrial para o acabamento das peças. São responsáveis pelo sustento da casa, dos filhos e netos e acumulam diversas funções no âmbito dos espaços da produção e da reprodução social.

Embora o trabalho da costureira seja praticamente invisível para a maioria das pessoas que circulam pelas ruas do bairro, elas podem ser localizadas com certa facilidade no território da Federação. Algumas colocam placas feitas à mão, na porta de casa ou em postes na rua onde moram para divulgar o trabalho, outras são conhecidas pelos vizinhos, pelos próprios clientes, de boca em boca ou pelas redes sociais na internet. Elas não se conheciam entre si.

Nos relatos, algumas costureiras destacam que aprenderam a costurar ainda na infância ou adolescência com algum familiar. Nessa fase, elas costuravam para as bonecas ou vestuário para os irmãos mais novos. "Minha mãe costurava... e minha mãe que me criou que é minha tia também costurava, eu morava com ela... aí ficava olhando ela fazer, aí comecei a aprender [...]" (Madalena, 40 anos).

Valdira começou a costurar como aprendiz aos 17 anos, no atelier de costura instalado próximo a sua casa. Para ela a oportunidade de entrar nesse atelier significou uma mudança de vida, pois antes vivia de "bicos" como faxineira.

Observa-se que essas mulheres continuam inseridas em atividades pouco reconhecidas e valorizadas e tipicamente femininas. No cotidiano elas precisam conciliar habilida- 
des físicas e cognitivas exigidas pelo acúmulo e superposição de tarefas: o trabalho remunerado, o trabalho doméstico e o cuidado de filhos e netos. Realizam jornadas de trabalho intensas e extensas, no espaço comum da casa, sem distinção dos tempos de trabalho, de não trabalho e de descanso ${ }^{12}$.

A trajetória de trabalho das mulheres pretas, com baixa escolaridade e qualificação profissional, investigadas no estudo é marcada pela ausência de acesso à proteção social de direitos trabalhistas e previdenciários, más condições de saúde e qualidade de vida. A busca pela autonomia no trabalho em domicílio é confrontada por elementos estruturais e simbólicos que dizem respeito à posição de classe, gênero e raça dessas mulheres. Para Hirata ${ }^{13}$ a interseccionalidade de gênero, classe e raça, é um recurso para refletir conjuntamente sobre as formas de dominação. A exploração realizada neste estudo destaca elementos de acentuação da clivagem da produção no âmbito do espaço da reprodução social e delineia elementos de resistência de mulheres ao sustentarem o estar fora da fábrica ${ }^{13}$.

A inserção das mulheres no mercado de trabalho não as isenta da execução das atividades domésticas e do cuidado com os filhos, papel culturalmente instituído, que reforça a inserção das mulheres no trabalho precarizado, pela possibilidade de contratação de jornadas em tempo parcial, sem garantias sociais e trabalhistas, com salários reduzidos e ou pagamento por produção².

Assim o trabalho em domicílio deixa de ser uma escolha e passa a ser imposto pela necessidade de conciliar a geração de renda, as funções domésticas e o cuidado com os filhos ${ }^{3}$.

A precariedade de trabalho e as condições de vida decorrentes da dinâmica de vida dessas mulheres reforçam a exclusão social e a vulnerabilidade. O trabalho domiciliar das costureiras expõe aspectos da vulnerabilidade social decorrente da saída do trabalhador formal para o setor informal, mas também atua como modulador de vulnerabilidade, quando se configura como meio da manutenção da renda familiar. Apesar de manter, ainda que de modo precário o sustento da família, o trabalho em domicílio apresenta características de ser sazonal, propiciar baixa remuneração e dificulta a inclusão desse grupo no sistema de proteção social, por meio da contribuição à previdência social.

Ambiente, condições de trabalho, saúde e relação familiar

O trabalho das costureiras desenvolve-se, geralmente em um cômodo adaptado para a colocação das máquinas de costura e materiais necessários à atividade, na sala ou no quarto mais próximo da entrada da casa, para facilitar o atendimento dos clientes. Algumas das casas estão localizadas em ruas cujo acesso acontece somente a pé, por serem estreitas ou com escadarias. A utilização da residência como espaço de trabalho modifica a rotina da trabalhadora e de sua família. Todos convivem com o barulho das máquinas, com os pedaços de tecidos espalhados pelo 
chão, com a presença de clientes nos diversos horários do dia, com os momentos de estresse dos períodos de maior demanda da produção e com o adiamento de algumas atividades domésticas para conclusão das encomendas.

Os ambientes de trabalho, com frequência, dispõem de pouca iluminação natural e baixa ventilação, sendo a iluminação artificial inadequada para a execução de tarefas que exigem esforço visual. As máquinas ficam misturadas com os instrumentos, as linhas, agulhas, tesouras, revistas, os sacos com retalhos de peças costuradas, os tecidos espalhados pelo chão e outros equipamentos. As roupas confeccionadas e os tecidos ficam armazenados em sacos plásticos ou em armários antigos e prateleiras de madeira. Esse arranjo acarreta acúmulo de poeira e favorece o desenvolvimento de ácaros, a ocorrência de processos alérgicos e de acidentes, como cortes e quedas. Algumas casas não têm piso, com paredes de tijolos, sem reboco. $\mathrm{Na}$ maioria dos ambientes de trabalho visitados, as instalações elétricas são precárias, com fios expostos, gambiarras, o que pode favorecer a ocorrência de incêndios e acidentes por combustão.

A postura assentada em cadeiras ou bancos improvisados e ou adaptados, por longas horas, determina exigências musculoesqueléticas que favorecem o aparecimento de dores e lesões da coluna vertebral. Para compensar, são utilizadas almofadas para aliviar a pressão sobre o quadril. As máquinas ficam em bancadas ou em mesas adaptadas segundo as exigências da produção, ainda que não contemplem o conforto e os requisitos ergonômicos bem conhecidos e normatizados na legislação trabalhista.

Não existe horário fixo de trabalho, com interferência contínua nas atividades pessoais e na dinâmica familiar. Nos períodos de maior demanda de pedidos, a jornada de trabalho pode chegar a 12 horas diárias ou mais. Próximo do final do ano, as trabalhadoras dormem pouco e trabalham nos finais de semana, sacrificando o lazer e a atenção aos filhos. Ultrapassam o limite do cansaço e a temática comum é "trabalhar até não aguentar".

[...] na semana passada (final do ano) porque tinha muita coisa para entregar e....e trabalho difícil, coisas difíceis, aí estava indo até dez horas... onze horas da noite... e confesso a você que... ir dormir onze horas, meia noite e acordar cinco horas é pauleira... horrível... horrível!!! Se tiver muito pedido, eu trabalho sábado e domingo também [...] (Rosa).

A sazonalidade é uma característica importante do trabalho das costureiras em domicílio, acarretando a intensificação do ritmo de trabalho em determinados períodos, alternando com períodos de baixa de produção. Essa situação gera insegurança quanto à renda e à própria sobrevivência. Essa dinâmica faz com que as trabalhadoras tenham que viver daquilo que ganham na época de maior produção, sem perspectivas de planejamento em longo prazo. Essa variação da produção tem repercussão na renda familiar, como traz o relato a seguir: 
Tem época que tem menos, chego a um salário, às vezes, até menos.... $\mathrm{Na}$ época que tem menos pedidos... Em torno de... quinhentos a mil reais, mas não todo mês, na época que tem mais... aí eu tenho mais, às vezes, mil a quinhentos reais, dois mil reais... (Rosa).

Mesmo sem garantias dos direitos trabalhistas ganhando para sobreviver e convivendo com a incerteza quanto às demandas de trabalho, as costureiras entrevistadas afirmaram não pretender retornar para o trabalho formal na fábrica ou a outro tipo de atividade. Segundo elas, os rígidos horários a serem cumpridos e metas a serem atingidas não compensam as possíveis garantias do emprego formal. Em casa e trabalhando por conta própria, elas têm maior controle sobre o tempo e mais autonomia. Dispõem de melhor margem de manobra de sua atividade, o que segundo elas afirmaram protege a saúde, mesmo sabendo que em muitos momentos essa margem é muito estreita. $\mathrm{O}$ depoimento a seguir ilustra esse pensamento.

Trabalhar fixo, eu não sei mais não viu... você não tem regalia, você não pode fazer... você não tem direito a estar levantando... você tem um tempo para levantar para fazer xixi, você tem um tempo para beber água... entendeu? $\mathrm{E}$ ai não dá certo não. Em casa, eu faço o que eu quero, dentro do meu limite, nas minhas condições aqui, eu levanto vou no banheiro a hora que eu quiser, desço e falo com mãe, subo... e na fábrica não... na rua não é assim não [...] (Valdira).

Essas observações reforçam o mito e ou a realidade de que em casa, elas são os próprios patrões, não estão subordinadas à gestão de trabalho taylorista, controlando o ritmo da linha de produção. Elas podem sair e voltar, parar a produção a qualquer hora, resolver outros problemas em paralelo, fazer pausas sem necessitar de autorização. São elas que fazem a gestão do trabalho, marcando o ritmo, a intensidade e a condição que conseguem suportar para cumprir os prazos de entrega para os clientes. Nesses relatos, trabalhar em casa garante melhor qualidade de vida, como afirma Valdira:

Trabalhar em casa, pela qualidade de vida... pela qualidade, pelo risco, estresse, não tem coisa pior do que você sair de manhã com a marmita, um sol quente desse, você subir escada, subir ladeira, correr risco de ladrão, voltar para casa, com a marmita suja, pegar ônibus cheio, não vale a pena não.

Esses relatos corroboram o comentário de Silva, Uziel e Rotenberg ${ }^{14}$ de que no trabalho domiciliar não se observa o mesmo controle do trabalho industrial ou do setor de serviços, existindo mais flexibilidade de horário e a liberdade de ir e vir. Trabalhar em casa expressa uma ideia de autonomia, de controle do tempo e da oportunidade de estar longe 
das ordens da fábrica, das pressões pelo ritmo de trabalho, das relações de trabalho, das exigências de tempo e do ritmo da produção. Isso não quer dizer que não existem formas de controle, mas estas se apresentam sob outras formas e seguem o ritmo da produção manual e artesanal, ou seja, o tempo está condicionado à quantidade dos pedidos de costura demandados e às questões ligadas a sazonalidade.

Como afirmam Pena, Freitas e Cardim ${ }^{15}$ sobre o trabalho artesanal das marisqueiras:

[...] o agravo à saúde emerge não da valorização direta do capital, mas de forma indireta por meio do baixo preço pago" pelo serviço [...] "as cadências extenuantes resultam da miséria, dadas às condições em que as marisqueiras são constrangidas ao sobre trabalho para evitar a fome e a marginalização da sua família" (p. 3390).

No dia a dia de trabalho, as costureiras estão expostas a cargas físicas, mecânicas, ergonômicas, fisiológicas e psíquicas que se somam e ou potencializam. A interação com os clientes, a modelagem, a compra dos insumos para executar a produção, o provimento da casa, entre outros se sobrepõem no âmbito da produção e da reprodução social, com consequências e danos para a saúde dessas trabalhadoras, que se manifestam de modo diferenciado e se refletem na qualidade de vida e de suas famílias e na interação com os serviços de saúde.
A multiplicidade de funções executadas por essas mulheres submete o corpo a posturas viciosas para diversas estruturas corporais, a cabeça e o pescoço, os membros superiores e inferiores, assim como a mente à situações de estresse e ansiedade constante. As costureiras relataram diversos problemas de saúde, agudos e crônicos, problemas como: alergias, hipertensão arterial, diabetes, circulação, estômago, depressão, dores musculoesqueléticas e cansaço crônico. Alguns relatos sugerem a sobrecarga musculoesquelética e quadro clínico de lesões por esforços repetitivos/distúrbio osteomuscular (LER-DORT). No relato abaixo, é possível perceber o sofrimento de Madalena enfrentando os sinais de esgotamento físico e tentando manter-se em atividade.

[...] sinto muitas dores... nos braços... nas costas... coluna... eu tenho tendinite né... inchava muito... agora de um tempo para cá ele melhorou bastante... dói assim.... essa semana mesmo estava doendo... mas já é menos... Também tenho problema na cervical... Fiz tratamento no SARA... é... é toda desajuntada...(risos) é... eles falam que eu tenha cervicalgia crônica... tenho dores... tenho que tomar remédios, fazer exercícios... essas coisas, né? (Madalena).

Bernardino e Andrade ${ }^{17}$ destacam que trabalhadores inseridos na informalidade e com vínculos precários estão à mercê da própria sorte, desamparados da proteção tra- 
balhista e previdenciária. Essas trabalhadoras carregam a responsabilidade de não adoecer, pois isto comprometeria o próprio sustento e o da família. Madalena relata episódio quando a decisão era entre trabalhar ou passar necessidade. A decisão por trabalhar prevaleceu, recorrendo ao tratamento prescrito como alívio da dor:

Mesmo com a dor tenho que produzir... porque eu vivo disso né? Se eu não produzir.... Já aconteceu de eu está debilitada e não poder costurar... aí eu mesmo arranquei... eu fiquei com um braço enfaixado... e aí tive que arrancar [gesso]... porque eu fiquei trabalhando com uma mão só... aí não dava né... aí eu mesmo tirei...na gravidez mesmo tive que voltar a trabalhar com 09 dias de parida [...] (Madalena).

A invasão da residência pelo trabalho remunerado acarreta formas de adoecimento que vão além da saúde do trabalhador, atingindo também outros membros da família. Madalena refere que não consegue dar atenção à filha devido à grande demanda de trabalho e que os momentos de lazer ficam sacrificados em prol do trabalho. Quando não está na escola, a criança passa a maior parte do dia brincando sozinha e manifesta sinais da necessidade de atenção da mãe em mudanças de comportamentos.

Ela está fazendo acompanhamento com a psicóloga aí do posto... aff... Ave Maria,
Jesus da misericórdia. Fiquei em tempo de enlouquecer com essa menina... Não era Bia... transformada... fez coisas que você nem imagina...Fazendo coisas que ela não faz... entendeu? Ela encheu a cama de brinquedo... depois forrou bem forradinho para eu deixar encima para doer minhas costas... cortou meu varal todo... Beatriz nunca fez essas coisas. Eu nunca perdi um pedaço de pano aqui por causa de Bia... nada... entendeu? Nunca! (Madalena).

A precarização observada no trabalho domiciliar dessas costureiras apresenta repercussão na saúde e na qualidade de vida de todo o âmbito familiar. A família está totalmente envolvida nesse contexto de trabalho e acaba perdendo a privacidade do lar, visto que todos os membros precisam se adaptar àquele ambiente de trabalho instalado dentro de casa.

Em relação aos cuidados de saúde, apesar da exaustiva jornada diária dessas trabalhadoras, elas costumam frequentar à unidade de saúde da Federação ou outros serviços de saúde para buscar assistência. Geralmente, as pessoas são atendidas por uma queixa aguda ou por pertencer a um grupo de atenção ou está numa etapa dos ciclos de vida abordados pela atenção básica, tais como: saúde da mulher, saúde do homem, saúde do idoso, etc.

Nesse ponto, elas também trazem à tona a dificuldade de acompanhamento da saúde no sistema único de saúde (SUS). Al- 
gumas já frequentaram a unidade e outras ainda frequentam, seja para cuidado próprio, seja para o acompanhamento de algum familiar. No entanto, esperar pelo atendimento demanda tempo e elas não podem esperar. Muitas vezes, chegam a frequentar uma unidade de saúde bem longe de casa, pois tem agilidade de atendimento. Para procedimentos fora da unidade de saúde e/ou de acompanhamento especializado, acabam procurando por um serviço particular.

Apesar de todas as costureiras participantes dessa pesquisa estarem sendo ou terem sido atendidas na USF da Federação, nenhuma delas referiu se algum profissional tinha estabelecido uma associação do seu quadro de saúde ou queixa com a sua condição de trabalho. Isso traz à tona lacunas que ainda existem na implantação de políticas públicas voltadas para atenção à saúde dos trabalhadores. Essas ações estão distantes para o trabalhador do território, mesmo para processos de trabalho extradomiciliares, visíveis para toda a população. A distância é ainda maior, quando se fala em trabalho domiciliar, invisíveis para a sociedade ${ }^{18,19}$.

Diversos estudos abordam os desafios sobre o reconhecimento dos usuários enquanto trabalhadores. Silva, Uziel e Rotenberg ${ }^{14}$ destacam que o reconhecimento dos usuários enquanto trabalhadores deveria ser iniciado no cadastramento das famílias pelos ACS e continuaria no acolhimento, na consulta clíni- ca, na visita domiciliar, nos grupos operativos, entre outros momentos de interação entre os usuários e a equipe, no entanto, outros autores evidenciam que o usuário não é visto como trabalhador e, quando isso acontece, predomina a compreensão dele está inserido no setor formal ${ }^{20}$.

\section{CONCLUSÃO}

A exploração de situações de trabalho domiciliar de costureiras em um território da ESF expôs vulnerabilidades nesse tipo de trabalho informal e acesso reduzido aos serviços de saúde da APS. A invisibilidade do trabalho domiciliar no território de abrangência de uma USF em área urbana, por parte dos profissionais de saúde, é acompanhada também pelo não reconhecimento da USF como um espaço para o cuidado dos agravos relacionados ao trabalho pelas costureiras.

Mulheres negras, de baixa escolaridade e arrimos de famílias monoparentais, inseridas no mercado informal, estão desprovidas de proteção social para o não trabalho, por motivo de doença ou envelhecimento.

É relevante a compreensão sobre os impactos da vivência da precarização do trabalho sobre os indivíduos, a saúde e a proteção social. Ampliar a visibilidade do trabalho presente no território da ESF permanece como desafio para a implantação da PNSTT. 


\section{REFERÊNCIAS}

1. Antunes, R. Adeus ao trabalho? ensaio sobre as metamorfoses e a centralidade do mundo do trabalho. São Paulo: Cortez; Campinas: Editora da Universidade Estadual de Campinas, 2006.

2. Neves MA, Pedrosa CM. Gênero, flexibilidade e precarização: o trabalho a domicílio na indústria de confecções. Soc e Estado. 2007; 22(1):11-34.

3. Carvalhal TB. O trabalho domiciliar feminino como estratégia de sobrevivência e/ou imposição do capital? Rev Pegada [Internet]. 2007;8(2):131-148.

4. Brito JC. Enfoque de gênero e relação saúde/trabalho no contexto de reestruturação produtiva e precarização do trabalho. Cad Saude Publica. 2000;16(1):195-204.

5. Brasil. Portaria $n^{0} 1.823$ de 23 de agosto de 2012. Institui a Política Nacional de Saúde do Trabalhador e da TrabaIhadora. Ministério da Saúde. 2012; 23 ago.

6. Dias EC, Silva TL. Possibilidades e desafios para a atenção integral á saúde dos trabalhadores na atenção primária. In: Saúde do trabalhador na atenção primária à saúde: possibilidades, desafios e perspectivas. Belo Horizonte: Coopmed; 2013

7. Ayres JRCM, França I, Junqueira G, Saletti HC. O conceito de vulnerabilidade e as práticas em Saúde. Novas perspectivas e desafios. In: Czeresnia D, Machado C, organizadores. Promoção da Saúde: conceitos, reflexões, tendências. 2a ed. Rio de Janeiro: Fiocruz; 2009. p. 12143.

8. Denzin, NK, Lincoln, YS. O planejamento da pesquisa qualitativa: teorias e abordagens. 2. ed. Porto Alegre: Artmed, 2006.

9. Minayo MC de S, Guerriero ICZ. Reflexividade como éthos da pesquisa qualitativa. Cienc e Saude Coletiva. 2014.

10. Salgado RS. A Performance da Etnografia como Método da Antropologia. Antropológicas. 2015;13:27-38.

11. Cadoná E, Scarparo H. Construcionismo social na atenção básica: Uma revisão integrativa. Cienc e Saude Coletiva. 2015; 20(9):2721-2730
12. Silva DM, Lima ADO. Mulher, trabalho e família na cena contemporânea. Context Clínicos [Internet]. 2012 Jun $18 ; 5(1)$.

13. Hirata H. Gênero, classe e raça Interseccionalidade e consubstancialidade das relações sociais. Trab Educ e Saúde. 2014; 4(1):199-204.

14. Silva FR, Uziel AP, Rotenberg L. Mulher, tempo e trabalho: o cotidiano de mulheres comissárias de voo. Psicol Soc. 2014;26(2):472-482.

15. Pena PGL, de Freitas M do CS, Cardim A. Trabalho artesanal, cadências infernais e lesões por esforços repetitivos: Estudo de caso em uma comunidade de mariscadeiras na llha de Maré, Bahia. Cienc e Saude Coletiva. 2011; 16(8):3383-3392.

15. Druck G, Dutra R, Silva SC. A contrarreforma neoliberal e a terceirização: a precarização como regra. Cad CRH. $2019 ; 32(86): 289$.

16. Bernardino DCAM, Andrade M. O trabalho informal e as repercussões para a saúde do trabalhador: uma revisão integrativa. Abstr Resum. 2015; 7(IV):149-158.

17. Amorim LDA, Silva TL, Faria HP, Machado JMH, Dias EC Vigilância em saúde do trabalhador na atenção básica: Aprendizagens com as equipes de saúde da família de joão pessoa, Paraíba, Brasil. Cienc e Saude Coletiva. 2017; 22(10):3403-3413.

18. Brasil. Cadernos de Atenção Básica, $n^{\circ} 41$. Ministério da Saúde: Secretaria de Atenção à Saúde. Secretaria de Vigilância em Saúde, 2018.

19. Evangelista AIB, Pontes AGV, Silva JV, Saraiva AKM. A saúde do trabalhador na atenção primária à saúde: o olhar do enfermeiro. Rev RENE. 2011; 12(n. esp.):1011-1020.

\section{CORRESPONDÊNCIA}

Robson da Fonseca Neves

Rua Manoel Nóbrega Filho n. 20, casa 12

Intermares, Cabedelo-PB, CEP: 58.102.290

E-mail: robsonfisioba@gmail.com 